\title{
EL CONCURSO APARENTE DE LEYES EN LA LEGISLACIÓN NICARAGÜENSE
}

FABIOLA MARÍA PEÑA CASTILLO

Profesora de Derecho Penal

Universidad Centroamericana

\section{Introducción}

$\mathrm{Al}$ introducimos al estudio del concurso aparente de leyes, nos damos cuenta que esta figura ha sido abordada por diversos autores tanto de manera doctrinal como interpretativa a través de sus comentarios respecto a la aplicación legislativa sobre la misma.

A menudo y a pesar del conocimiento o poco conocimiento que se tenga sobre el tema del concurso aparente de leyes o de normas, como también se le conoce, se nos plantea la confusión entre el concurso de delitos y del concurso aparente de leyes. Sin embargo, hablar de ellos es complejo ya que la línea que les divide puede verse tan delgada como un hilo o no verse del todo.

Es por ello que este trabajo investigativo tiene por objeto analizar la figura del concurso aparente de leyes en el ámbito dogmático y en la legislación nicaragüense con la finalidad de poder brindar a los beneficiarios del mismo un documento que les permita conocer tanto la teoría como la práctica de dicha figura a través de ejemplos en donde observarán y podrán crear sus propios criterios respecto a forma correcta de aplicación y así profundizar en el estudio del Derecho Penal tanto en su parte general como en la especial.

En Nicaragua sólo se conocía lo que la doctrina planteaba respecto a la teoría de los concursos de delitos y el concurso aparente de leyes ya que el legislador no había recogido dichas figuras en la norma penal. 


\section{Revisla de Perecho}

Lo cual en mi opinión, constituía una problemática de aplicación de las mismas para fundamentar las sentencias penales; ya que se desconocía el tratamiento jurídico penal de la figura del concurso aparente de leyes en la legislación nicaragüense por parte de los operadores del sistema judicial.

En la actualidad, con la entrada en vigencia de la Ley $641^{1}$, Código Penal de la República de Nicaragua, el Derecho Penal interno se ve fortalecido ya que le legislador ha acogido al concurso aparente de leyes y de los concursos de delitos dándole una ubicación sistemática como parte del título preliminar sobre las garantías penales y de aplicación de la ley penal, algo novedoso si se observa la historia que esta figura ha tenido dentro del Derecho Penal. Para la elaboración del artículo de investigación se utilizó la tesis jurídica dogmática prepositiva, ya que a lo largo de la misma se va cuestionando la aplicación de la institución del concurso aparente de leyes, sus aciertos y desaciertos dogmáticos de parte de los funcionarios de la administración de justicia.

\section{Principios concursales básicos}

De previo al abordaje de los principios concursales básicos es necesario saber qué se entiende por principio y el por qué de la existencia de principios concursales básicos dentro del Derecho.

Debemos remontarnos a las fuentes que origina el Derecho Objetivo y hablar de las fuentes del Derecho en sentido técnico, es decir, al origen del mismo, a los modos o formas mediante los que, en una sociedad constituida, se manifiestan y determinan las reglas jurídicas como preceptos concretos y obligatorios.

Las fuentes directas del Derecho doctrinalmente se dividen en dos: la Costumbre, integrada por la expresión espontánea y directa de la conciencia social y la Ley, integrada por la expresión reflexiva a través de los órganos oficiales. Entre las fuentes indirectas se cita a la jurisprudencia, el derecho natural, el derecho científico, las leyes

La Ley N 641, Código Penal de la República de Nicaragua, fue publicada en La Gaceta, Diario Oficial $\mathrm{N}^{\circ} 83,84$, 85,86 y 87 en las fechas $05,06,07,08$ y 09 de mayo de 2008, entró en vigencia el 09 de julio de 2008 en toda la república.

2 BANADES GASSET, Conceptos Fundamentales del Derecho, 1982, 21. 


\section{Revisla de Perecho}

históricas y derogadas, la analogía y la equidad. ${ }^{2}$

Se entiende por Principios Generales del Derecho aquellos que sirven de fundamento al Derecho positivo de cada país y pueden inducirse por vía de generalizaciones sucesivas de las disposiciones particulares de la ley. Estos actúan como fuente subsidiaria respecto a las demás, también como función autónoma de fuente del Derecho, teniendo en sí un significado informador de la Ley y la Costumbre. ${ }^{3}$

Para el abordaje del concurso aparente de leyes y los concursos de delitos, la doctrina ha elaborado ciertos principios básicos ${ }^{4}$ que contribuyen a clarificarnos su estudio y aplicación. Por ello, cuando nos referimos a la existencia de pluralidad de delitos es necesario plantearse escenarios en los cuales podamos visualizar la actividad delictiva, de tal forma que nos permitan brindar conclusiones claras a cada planteamiento.

ARCE AGGEO ${ }^{5}$, plantea dos parámetros ${ }^{6}$ que fundamentan la pluralidad de delitos: la aceptación y aplicación, de donde se desprenden los principios concursales. Así entonces, la aceptación consensual de la aplicabilidad de pena en concreto a cada delito, aplicando la sanción a cada uno de ellos. De ahí el primer principio concursal: cada delito deber ser penado -quot delicta tot poenae-.

Al respecto, el principio de legalidad tiene su ingerencia dentro del principio concursal abordado, ya que además de gozar de rango constitucional 7 junto a las garantías mínimas engloban los preceptos básicos en materia penal y procesal penal; comporta dos exigencias:

a) La necesidad de predeterminación normativa de las conductas ilícitas y de las sanciones correspondientes, mediante preceptos jurídicos que permitan predecir, con suficiente grado de certeza, las conductas sancionables así como las penas imponibles; $y$

b) El rango de las normas tipificadoras ha de ser el de una ley. ${ }^{8}$

BANADES GASSET, Conceptos Fundamentales del Derecho, 1982, 25.

4 Es necesario aclarar que en el derecho penal muchos preceptos legales se auxilian de principios o reglas determinadas.

5 ARCE AGGEO, Concurso de delitos, 1996, 22-24.

6 ARCE AGGEO elabora y explica dos parámetros - aceptación y aplicación- de los que desprende a los dos principios concursales básicos.

7 Artículo 33 Constitución Política de Nicaragua.

8 FERNÁNDEZ MARTÍNEZ, Diccionario Jurídico, 2002, 585. 


\section{Revisla de Derecho}

Nuestra legislación penal establece que son delitos y faltas las acciones u omisiones dolosas o imprudentes calificadas y penadas, tanto en el Código Penal como en leyes especiales"; hay que recordar que la comisión de un hecho delictivo trae como consecuencia la imposición de una pena. De ahí que si el autor de un hecho delictivo ha cometido más de un hecho ninguno debe quedar impune. Esto ha sido llamado como el "merecimiento de penalidad" por ZAFFARONI ${ }^{10}$, entendido como el merecido por el delito cometido afirmando la existencia de una conducta típica, antijurídica y culpable; aún cuando se considera inoperante por la exclusión de la coerción penal en casos determinados.

Esta problemática corresponde a la teoría de la pena, a la cual se recurre con motivo de aplicar la pena en el caso concreto de la hipótesis concursal pero no como merecimiento sino como operatividad de la misma. ${ }^{11}$

El segundo parámetro se desprende de lo establecido en la norma penal como garantía individual, la única persecución ${ }^{12}$, por tanto no procederá la aplicación de más de una pena por cada delito, garantía reconocida bajo el aforismo - ne bis in idem ${ }^{13}$ - dentro del Derecho y que constituye por ende el segundo principio concursal.

La Constitución Política Nicaragüense en su artículo 34 numeral 10) se establece como garantía mínima el no ser procesado nuevamente por el delito por el cual fue condenado o absuelto mediante sentencia firme. Por tanto, se afirma que este segundo principio tiene rango constitucional.

Para resumir podemos decir que con antelación los principios sirven para auxiliarnos y enmarcar las pautas de carácter doctrinal que deben seguirse. Por ello estos principios básicos concursales abordados contribuyen al estudio del concurso aparente de leyes teniéndolos como una regla general que deberá aplicarse observando y tomando en cuenta las reglas específicas que la ley designe para cada caso en concreto.

9 Véase artículo 21, Ley $\mathrm{N}^{\circ}$ 641, Código Penal de Nicaragua.

10 ZAFFARONI, Tratado de Derecho Penal Parte General, 1988, 53.

11 ARCE AGGEO, Concurso de delitos, 1996, 23-24.

12 La legislación procesal nicaragüense establece en su artículo 6 como garantía individual la única persecución, debiendo entenderse que quien haya sido sobreseído, absuelto o condenado por una resolución firme no podrá ser sometido a nueva persecución penal por los mismos hechos. Artículo 6, Ley ํo 406, Código Procesal Penal de la República de Nicaragua.

13 El principio de ne bis in idem prohíbe en la esfera penal que una persona sea castigada más de una vez por la misma infracción; y en la procesal, que se le juzgue más de una vez por el mismo hecho. ORTS BERENGUER, Compendio de Derecho Penal, 2004, 61. 


\section{Unidad de acción o de hecho}

¿Unidad de acción o de hecho? Es la interrogante que muchos doctrinarios se hacen al plantearse la aplicación del concurso aparente de leyes y el concurso de delitos. Cuando hablamos de concurso de delitos nos enfocamos en determinar si hay una o varias acciones; a su vez debe examinarse el fin trazado por el autor, su plan y el tipo penal que corresponde.

MUÑOZ CONDE al referirse al concurso de delitos y de leyes identifica dos factores que contribuyen a conceptualizar a la unidad de acción el factor final y el factor normativo-. Respecto al primero, lo refiere como la voluntad que rige y da sentido a una pluralidad de actos físicos aislados, ejemplificándolo al azar a la comisión de un asesinato, en el cual la voluntad manifiesta de matar reúne una serie de actos tales como disponerse a conseguir una pistola, cargar con balas la misma, intimidar a la víctima, apuntar y disparar a la víctima. ${ }^{14}$

El segundo, el normativo, se refiere a la estructura del tipo delictivo en cada caso particular. De ahí que los actos dentro de un proceso causal puedan dar origen a diversos actos particulares que por sí solos constituyan tipos delictivos y viceversa, es decir, pluralidad de tipos ante pluralidad de conductas, pero no siempre la pluralidad de conductas determina la pluralidad de tipos que se suscitan. De donde cabe afirmar que puede existir concurso aparente de tipos, unidad de conductas por efecto del tipo o concurso ideal a la inversa. ${ }^{15}$

La palabra "hecho" es utilizada a menudo como sinónimo de "acción" dentro del Derecho Penal, en lo que varios autores argumentan diversas acepciones que las difieren y en las que se asemejan. ${ }^{16}$

Los criterios propuestos para determinar a la unidad de hecho son diversos. La más precisa es la opinión de quienes sostiene que el criterio para valorar un hecho como unitario en el Derecho Penal sólo puede ser jurídico y según se desprende del sentido del tipo aplicable.

14 MUÑOZ CONDE, Derecho Penal Parte General, 1998, 513.

15 ARCE AGGEO, Concurso de delitos, 1996, 44.

16 Al respecto MIR PUIG, Derecho Penal Parte General, 2002, 626 y ss.; ARCE AGGEO, Concurso de delitos, 1996, 44 y ss; y MUÑOZ CONDE, Derecho Penal Parte General, 1998, 512 y ss. 
La terminología de unidad de hecho ${ }^{17}$ tiene ventaja sobre la unidad de acción porque permite vincularla a la unidad típica sin desconocer que el tipo describe a menudo varias acciones, de donde se afirma que toda unidad típica supondrá unidad de hecho, aunque implique en ciertos casos pluralidad de actos típicos.

ARCE AGGEO $^{18}$ concibe al hecho también como ejercicio de una actividad final, la cual estructura en los siguientes pasos:

a. El autor se propone un fin determinado;

b. Selecciona los medios para llevarlo a cabo;

c. Pone en marcha la causalidad.

Lo cierto es que el Derecho Penal Nicaragüense está basado en la unidad de hechos y no de acciones; y sobre ello es que está basado el Código Penal vigente.

\section{Pluralidad de acciones y unidad de delitos}

Para Hruschka, en supuestos de pluralidad de hecho sería "inadecuado" hablar de "concurso de leyes", pues éstos se diferenciarían de aquéllos de forma significativa: concurso de leyes qua especialidad y qua subsidiariedad. Con estos términos debiera expresarse un concepto claro y preciso, la realización simultánea de dos (o más) supuestos de hecho delictivos a través de un idéntico acto. ${ }^{19}$

Cuando tal identidad de acto no existe, prefiere Hruschka hablar de "concurso real impropio" en el cual "el autor no es condenado por un hecho, a pesar de que el mismo cumple todas las condiciones del concepto de hecho punible, y ello por cuanto dicho hecho se entiende copenado por medio del castigo en virtud de otro hecho distinto". Según Hruschka, tres serían los casos en que estaríamos ante un "concurso real impropio": el de los actos anteriores copenados, el de los actos posteriores copenados y el de los actos acompañantes copenados, donde a pesar de existir simultaneidad entre los actos en cuestión, no habría en cambio la identidad que requeriría el concurso de leyes. Sin embargo, la referida autora no ofrece criterios particulares para determinar cuándo se está ante uno de esos actos copenados y cuándo ante un "concurso real propio", remitiendo para ello a la doctrina y jurisprudencia tradicionales. ${ }^{20}$

17 MIR PUIG, Derecho Penal Parte General, 2002, 626 y ss.

18 ARCE AGGEO, Concurso de delitos, 1996, 32.

19 MATUS, La Teoría del Concurso (Aparente) de Leyes en la Dogmática Alemana, 2001, (en línea).

20 MATUS, La Teoría del Concurso (Aparente) de Leyes en la Dogmática Alemana, 2001, (en línea). 
Por determinación legal o elaboración jurisprudencial, una pluralidad de acciones del mismo sujeto da lugar a un único delito. Esto ocurre: en los tipos combinados, en los que la ley, a pesar de existir varios actos distintos, aprecia unidad de acción; por ejemplo, el robo con violencia o intimidación en las personas ${ }^{21}$. En los tipos reiterativos, que sin presuponer variedad de actos volitivos, cuándo éstos se dan la ley los configura como una sola acción; por ejemplo, escándalo público ${ }^{22}$. En el delito permanente, que si bien se consuma por un solo hecho, se producen otros posteriores al mantenerse voluntariamente la situación antijurídica creada; y en el delito continuado, formado por varias acciones homogéneas en conexión interna, realizadas en distinto tiempo pero en análogas ocasiones, que infringen la misma norma jurídica.

La frontera entre una y otra clase de concursos se sitúa en la unidad o pluralidad de hechos. Respecto al concurso real y concurso ideal de delitos se explica, dicha frontera, en el significado del término "hecho" ya que se trata de interpretar el sentido del término hecho, pues en él reside la clave para determinar una y otra clase de concursos. ${ }^{23}$

\section{Concurso de delitos}

Los problemas concursarles se manifiestan cuando una sola acción o varias acciones ejecutan varios tipos delictivos, de donde se desprenden el concurso real, concurso medial e ideal; de los que me referiré sin ahondar en profundidad, ya que el tema central es el concurso aparente de leyes.

Existe concurso real o material cuando una pluralidad de hechos de un mismo sujeto constituye una pluralidad de delitos. ${ }^{24}$ Lo que equivale a decir que dicho concurso requiere pluralidad de infracciones, unidad de sujeto y de enjuiciamiento, pluralidad del objeto valorado en las diversas infracciones. 25

21 Véase artículo 224 Ley $\mathrm{N}^{\circ}$ 641, Código Penal de Nicaragua.

22 Véase artículo 537 Ley N 641, Código Penal de Nicaragua.

23 VIVES ANTON, Comentarios al Código Penal, 1995, 430-431.

24 MIR PUIG, Derecho Penal Parte General, 2002, 636.

25 VIVES ANTON, Comentarios al Código Penal, 1995, 430. 
La legislación nicaragüense regula el concurso real en su artículo 82 Código Penal, ${ }^{26}$ en el que se establece que a la persona responsable de dos o más delitos o faltas se le impondrán todas las penas correspondientes a las diversas infracciones para su cumplimiento simultáneo, según su naturaleza y efectos.

La doctrina fundamenta al concurso real en el principio de acumulación jurídica, las razones acogidas por CORDOBA RODA son: la primera es que se halla en la finalidad correcta de la pena, que se desvanecería si la duración de la misma supera los términos naturales de la existencia humana. ${ }^{27}$ La segunda, es la existencia del desprestigio hacia los tribunales por la imposición de largas penas privativas de libertad. Y la tercera, porque la acumulación absoluta llevaría a castigar más severamente un cierto número de infracciones de gravedad media, que un delito de extrema gravedad. ${ }^{28}$

Ejemplificando al concurso real entonces cuando un sujeto es condenado por seis homicidios, delito sancionado en el artículo 138 Código Penal con prisión de diez a quince años; en concurso real se sancionará a razón de diez años cada uno, la suma de todas las penas corresponde a 60 años, que es lo que se le impone en la sentencia, donde se observará la acumulación material. No obstante, por el principio de acumulación jurídica se deberá aplicar lo estipulado en el párrafo tercero del artículo 82 Código Penal, de donde se desprende que la condena no podrá exceder el triple del tiempo de la condena más grave. En el caso que nos ocupa el triple de la más grave es 10, por ende la pena a cumplir será de 30 años ya que esta cifra queda en el límite máximo permitido por la norma constitucional y penal.

La doctrina también reconoce al concurso real retrospectivo, el cual se presenta cuandolos delitos en concurso no son juzgados simultáneamente

26 Continúa expresando el artículo $82 \mathrm{CP}$ que "cuando todos o algunas de las penas correspondientes a las diversas infracciones no puedan ser cumplidas simultáneamente por el condenado, se seguirá el orden de su respectiva gravedad para su cumplimiento sucesivo, en cuanto sea posible. No obstante lo dispuesto en los párrafos anteriores, el máximo cumplimiento efectivo de la condena no podrá exceder del triple del tiempo de la pena más grave que se imponga, declarando extinguidas las que excedan de dicho máximo que, en ningún caso, podrá se superior a treinta años de prisión, veinticinco años de inhabilitación absoluta o especial, un mil quinientos días multa y un año y medio de jornadas de trabajo en beneficio de la comunidad."

27 La constitución política de Nicaragua estipula como pena máxima de cumplimiento de la pena treinta años de prisión. Artículo 37 Constitución Política de Nicaragua.

28 VIVES ANTON, Comentarios al Código Penal, 1995, 430.

${ }^{2} 9$ Véase artículo 84 Ley $\mathrm{N}^{\circ} 641$, Código Penal de Nicaragua. 


\section{Revista de Derecho}

en un solo proceso. En este caso el agente es responsable de varios delitos, pero inicialmente fue procesado y condenado únicamente por alguno de ellos. Al descubrirse el o los delitos restantes con posterioridad a la primera sentencia ellos darán lugar a un nuevo juzgamiento.

Así el delito de juzgamiento posterior merece una pena inferior a la ya impuesta se debe dictar el sobreseimiento definitivo; en cambio, si la pena fuese superior a la aplicada, se debe realizar un nuevo juzgamiento e imponerse la nueva pena correspondiente.

Por otro lado, la técnica jurídica utilizada por los legisladores nicaragüenses redactó en la misma norma al concurso ideal y al medial, ${ }^{29}$ a pesar que conceptualmente difieren uno del otro y su abordaje es distinto. Nuestra legislación les regula -al concurso ideal y al medialcon la misma penalidad..$^{30}$

GONZÁLEZ CUSSAC, afirma que la doctrina mayoritaria, opinión que comparte, consideran al concurso medial como una hipótesis de concurso real que recibe el mismo tratamiento que el concurso ideal, pues pueden reconducirse a un mismo fundamento a efectos penológicos, en donde la unidad de hecho supone una menor culpabilidad..$^{31}$

Entonces existe concurso ideal cuando se conjuga un solo hecho y una pluralidad de infracciones; ya la misma norma penal la define como "en el que un solo hecho constituye dos o más infracciones”. ${ }^{32}$

Los autores ORTS BERENGUER Y GONZÁLEZ CUSSAC plantean el ejemplo clásico del concurso ideal, en el que el sujeto que resiste gravementeala autoridad, cuando sehallareen el ejército desusfunciones, causándoles lesiones importantes. En tal caso, nos encontramos ante un solo hecho (un solo resultado material) constitutivo de dos infracciones (delito de lesiones ${ }^{33} \mathrm{y}$ delito de atentado ${ }^{34}$ ). ${ }^{35}$

$30 \quad$ Véase artículo 85 Ley $\mathrm{N}^{\circ}$ 641, Código Penal de Nicaragua.

31 VIVES ANTON, Comentarios al Código Penal, 1995, 440.

32 Véase artículo 84 Ley $\mathrm{N}^{\circ} 641$, Código Penal de Nicaragua.

33 Los delitos de lesiones son conocidos también como delitos de resultado, son la oposición de los delitos de peligro. Por definición son aquellos que se consuman en el instante en que se produce el menoscabo o daño real al bien jurídico protegido. Se considera que en el delito de lesión o de resultado su alcance es de carácter individual o específico.

$34 \mathrm{Al}$ respecto, nuestra legislación regula el delito de atentado como obstrucción de funciones en su artículo 460 Ley $\mathrm{N}^{\circ}$ 641, Código Penal de Nicaragua.

35 ORTS BERENGUER, Compendio de Derecho Penal, 2004, 291. 
Por otra parte, el concurso medial ${ }^{36}$ se ve manifestado cuando uno de los delitos sea medio necesario para cometer otro. La doctrina mayoritaria ${ }^{37}$ se inclina por su entendimiento como un supuesto de concurso real, pero que recibe tratamiento penológico del concurso ideal por sus particularidades. Se argumenta que si se tratara de un supuesto de unidad de hecho su mención expresa sería totalmente superflua y, por tanto, contraria al principio de vigencia.

Lo relevante en observar al concurso medial es la dirección final de la voluntad, que va en sentido único, ya que la realización pasa por el empleo de medios necesarios para llevarlo a cabo, dando lugar a una consideración unitaria del actuar a efectos penológicos. Bien se observa en el caso en que un sujeto realiza falsificación de documentos públicos como medio necesario para la comisión del delito de estafa contra una financiera, por ejemplo.

MUÑOZ CONDE afirma al respecto que, cuando la conexión entre los diversos delitos es tan íntima que si faltase uno de ellos, no hubiese cometido el otro, se debe considerar todo el complejo delictivo como una unidad delictiva y no como dos delitos distintos; y que por ello la doctrina y la jurisprudencia exigen, que el concurso medial sea aplicable únicamente cuando exista una relación de necesidad, que debe ser entendida en un sentido real, concreto y restrictivo. ${ }^{38}$

Por ello, aunque parezca repetitivo, se considera el tema del concurso un problema de determinación de la pena, ubicado dentro del llamado, para la doctrina minoritaria, el quinto elemento dentro de la teoría del delito, la punibilidad.

No obstante, los concursos se han ampliado a dos supuestos más, uno derivado del otro pero ambos producto dela ficción jurídica pero necesaria para explicar el problema de la existencia de pluralidad de acciones constitutivas de un solo delito. Se trata pues del delito continuado y del delito en masa.

Originariamente, el delito continuado fue una institución que surgió para beneficiar al privado de libertad, al excluir sus diversas acciones

36 Véase artículo 84 Ley N 641, Código Penal de Nicaragua.

37 ORTS BERENGUER, Compendio de Derecho Penal, 2004, 293.

38 MUÑOZ CONDE, Derecho Penal Parte General, 1998, 516. 
delictivas de las reglas del concurso real, por la valoración de una sola o por lo menos como un solo delito. Pero la jurisprudencia española recurrió a ella cuando existían dificultades para probar las diversas acciones aisladas y por otras razones que no siempre han beneficiado a los privados de libertad. ${ }^{39}$ La continuidad temporal y espacial no es un requisito invariado del delito continuado pero puede ser un indicio de la continuidad.

Para el delito continuado se exigen dos elementos ${ }^{40}$ :

a. Objetivos

a.1. Unidad de sujeto activo. Existe factibilidad cuando se presenta un agente ejecutor único, esto es, uniformidad del sujeto que ejecuta la conducta típica; lo cual no significa que el actor sólo tenga que ser una persona pues la conducta continuada puede ser obra de varias que, mancomunadamente, tengan esta calidad, como cuando actúa un número plural de coautores. Véase aquí que el nexo de continuidad sólo se podrá predicar de quienes intervengan en todos ellos; en otras palabras, nada impide reconocer el nexo de continuidad al mismo autor (o autores) que han contado con distintos partícipes.

a.2. Unidad Normativa. La realización de actos constitutivos de una unidad de acción es indispensable cuando se infringe de manera reiterada la misma figura típica, aunque se pueda llevar a cabo también una de naturaleza semejante, la condición es que el bien jurídico afectado sea el mismo, es decir, la existencia de identidad de bien jurídico lesionado; o identidad de tipo violentado por el actor.

Así las cosas, puede haber nexo de continuación entre un tipo simple y uno calificado; entre una conducta en grado de tentativa y otra del tipo penal, o al revés (acto consumado seguido de tentativa); o entre la ejecución del tipo básico y el agravado.

Lo importante es que los diversos actos obedezcan a una misma idea final, que encajen en un mismo supuesto de hecho o tipo penal, y se lleven a cabo con igual dinámica comisiva u omisiva.

39 MUÑOZ CONDE, Derecho Penal Parte General, 1998, 519.

40 Véase a MIR PUIG, Derecho Penal Parte General, 2002, 629. ZAFFARONI, Manual, No 435, 624; les divide en cuatro elementos que básicamente se subdividen en los dos elementos mencionados por MIR PIUG y que es el esquema que se presenta por considerarse más didáctico. 
a.3. Exclusión de ofensas a bienes jurídicos altamente personal. Se acepta elnexodecontinuación cuandolos bienesjurídicosafectados no son de aquellos calificables como altamente personales - los que comporten una «afección directa al mantenimiento y desarrollo de la personalidad de otro»-, por lo cual si se lleva a cabo una conducta continuada que afecte a uno de esos bienes jurídicos se deberá apreciar una figura distinta: un concurso ideal homogéneo ${ }^{41} \mathrm{o}$ un concurso material; naturalmente, si el titular del bien jurídico es el mismo, se acepta la continuación delictiva sin importar la clase de bien jurídico afectado.

a.4. Unidad o pluralidad de sujeto pasivo del delito. Se exige que la conducta sólo recaiga sobre el mismo titular del bien jurídico (el sujeto pasivo del delito), lo cual no la descarta cuando se tratare de diversos sujetos pasivos de la acción o de distintos perjudicados. No obstante, se ha abierto paso en la discusión la posibilidad de que el sujeto pasivo del delito sea plural como acontece cuando los bienes jurídicos afectados no son altamente personales, o en el llamado delito masa.

Además se tienen por aceptados ciertos elementos objetivos de carácter complementarios tales como:

- Empleo de medios o procedimientos semejantes

- El aprovechamiento de ocasiones idénticas, esto es, que haya unidad o identidad de ocasión de tal manera que los diversos segmentos de la conducta final se lleven a cabo en circunstancias fácticas similares $o$ asimiladas.

- Existencia de cierta conexión espacio - temporal, pues si el actor lleva a cabo diferentes actos (incluso distintas acciones) sin mediar el nexo de continuidad, no se podrá hablar de delito continuado. Ello no implica que tales actos se tengan que ejecutar en un lapso breve sino que se debe dejar a la discrecionalidad de la autoridad competente el juzgamiento de la situación - lo cual demuestra que es una cuestión puramente procesal-, de tal manera que él aprecie si ellos se han producido o no con cierta periodicidad o ritmo, dependiendo de si pueden ser o no abarcados dentro del plan delineado por el actor.

41 Recordemos que se habla de concurso ideal homogéneo cuando los delitos cometidos a través del mismo hecho son iguales; y heterogéneos cuando los delitos son distintos. 
b. Subjetivo:

b.1. Un dolo unitario (factor final o plan común). Como he dicho constituye una referencia subjetiva, la cual establece el primero y fundamental requisito que inspira la existencia del delito continuado en donde subsiste un dolo unitario, así lo denomina la jurisprudencia española, en el sentido que responda a una unidad de resolución y de propósito criminal. La ley exige por ende, una especia de culpabilidad homogénea, un plan premeditado en donde se vaya a realizar varios hechos delictivos, pero siempre con la presencia de elementos comunes que evidencien una idea global, es decir, una "unidad del plan" tal como lo refiere la jurisprudencia..$^{22}$

A manera de ejemplo podemos decir que el delito continuado tiene que ver con el principio de proporcionalidad ${ }^{43} \mathrm{y}$ el de lesividad ${ }^{44}$. En el que Juan y Pedro son empleados bancarios; ambos deciden sustraer un millón de córdobas del banco; Juan, que es decidido y audaz, toma $\mathrm{C} \$ 100.000$ por día, entonces, durante 10 días sustrae $\mathrm{C} \$ 1.000 .000$. Ambos son acusados. Juan, que se llevó los C $\$ 100.000$ en un momento, responde por hurto simple ${ }^{45}$. Actuó sin violencia, seis mes de prisión. Pedro responde a la acusación entablada y se le suman todos los máximos, por concurso, y podrá tener una pena de 20 años de máximo; lo cual es una injusticia y viola el principio de la equidad. De allí la importancia de su creación.

En este caso específico ambos van a ser penados por un hurto, porque uno se beneficia cuando se dan las circunstancias en donde hay unidad de resolución, unidad de dolo, identidad de víctima e identidad de tipicidad; cuando esto ocurre, habrá delito continuado y no será concurso. Respecto a Juan y Pedro, hay identidad de víctima: ambos al bando; hay identidad de tipo: que siempre hurte. No que haya robado (si rompe la caja); unidad de dolo: yo pienso llevarme $\mathrm{C} \$ 1.000 .000$ en diez veces.

42 VIVES ANTON, Comentarios al Código Penal, 1995, 422.

43 No sólo viola en principio de proporcionalidad, al que el judicial debe de guardar la debida adecuación entre la gravedad del hecho constitutivo de delito y la sanción aplicada; sino también el de equidad y justicia.

44 Artículo 7 Ley $\mathrm{N}^{\circ}$ 641, Código Penal de Nicaragua. Principio de Lesividad: "Solo podrá ser sancionada la conducta que dañe o ponga en peligro de manera significativa un bien jurídico tutelado por la ley penal."

45 Véase artículo 219 Ley $\mathrm{N}^{\circ}$ 641, Código Penal de Nicaragua, para efectos de verificar las penas.

46 FERNANDEZ MARTÍNEZ, Diccionario Jurídico, 2002, 252.

47 MUÑOZ CONDE, Derecho Penal Parte General, 1998, 519. 
De estas otras razones es que surge entonces el delito en masa, considerado una modalidad específica del delito continuado que se configura en supuestos en los que el agente actúa mediante una o varias acciones defraudatorias inspiradas en un mismo y único propósito criminal, realizadas frente a una pluralidad de sujetos pasivos indiferenciados, movido por un ánimo de lucro que abarca el importe total de lo percibido ilícitamente. Acá el sujeto pasivo aparece como una colectividad de personas, no vinculadas entre sí por in elemento jurídico común, aunque relacionadas por circunstancias episódicas o de intereses $\mathrm{y}$ a las que se ataca patrimonialmente. ${ }^{46}$

Por su parte, MUÑOZ CONDE afirma que existe delito en masa cuando una pluralidad de sujetos indiferenciados, personas anónimas, público en general, de las que el sujeto activo pretende extraer diversas cantidades de dinero con un propósito unitario de enriquecimiento, debe estimarse un solo delito por el importe global de la infracción cometida. ${ }^{47}$

El artículo 83 del Código Penal vigente, es donde se regula al delito continuado ocultando dentro de su contenido la regulación del delito en masa. Así el párrafo segundo de dicho artículo se puede interpretar como una acepción del delito en masa. En esta parte de la norma se regulan aquellas infracciones contra el patrimonio para las cuales se tomará en consideración el perjuicio total causado para efectos de imposición de la pena; para lo cual la autoridad competente impondrá una pena agravada hasta el doble del límite máximo de la pena correspondiente, si el hecho fuese de notoria gravedad y hubiese afectado a una generalidad de personas. ${ }^{48}$

\section{Concurso aparente de leyes}

\subsection{Concepto}

Se considera la existencia de concurso aparente de leyes cuando uno o varios hechos encajan en varios preceptos penales de los que únicamente puede aplicarse uno de ellos, con plena observancia de estimación

48 Si bien es cierto que el delito en masa como tal no está tipificado en nuestra legislación, el sólo hecho de invocar la parte final de dicho artículo hace que la esté aplicando, aunque bajo la figura del delito continuado. De tal forma, no tendría ningún problema o roce con el principio de legalidad en tanto está previsto en la ley.

49 Véase sobre el concepto de concurso aparente de leyes a MIR PUIG, Derecho Penal Parte General, 2002, 638; MUÑOZ CONDE, Derecho Penal Parte General, 1998, 520.

50 MATUS, La Teoría del Concurso (Aparente) de Leyes en la Dogmática Alemana, 2001, (en línea). 
del tipo a aplicar en tanto puede suponerse un bis in idem, ${ }^{49}$ lo cual supondría una sanción desproporcionada por excesiva; por este motivo, se restringe la aplicación a una sola norma.

Paul Merkel con sus aportes al Manual de Holtzendorf, es el primero en ofrecer un concepto de lo que él denominaba "casos de mero concurso de leyes", como expresase el mismo "Fällen einer bloßen Concurrenz von Gesetßen"; un principio general de solución para los mismos y una justificación para excluírlos de la regulación concursal común. Para el mismo, el concurso de leyes se distingue del concurso de delitos en general, entendido como una situación de "pluralidad de infracciones legales".50

En la doctrina subsisten dos concepciones distintas del concurso de leyes. La doctrina mayoritaria expresa que el concurso presupone que todos los preceptos en juego concurren de forma efectiva según la infracción descrita, de modo que el hecho cabe en todos y cada uno de los preceptos posibles de aplicación, pero únicamente uno de ellos debe ser aplicado. ${ }^{51}$

Otro sector observa que la concurrencia de distintos tipos es sólo aparente, ya que al realizar una correcta interpretación de los hechos se hace la selección para elegir el precepto correcto aplicable..$^{2}$

La concepción de la doctrina mayoritaria ha tenido aceptación debido a que permite que el precepto o todos los desplazados puedan ser tenidos en cuenta en combinación con el precepto preferente y pueda, de este modo, aplicarse.

$\mathrm{Al}$ respecto la doctrina dominante Alemana y su jurisprudencia afirman sobre la necesidad de tener presente el precepto desplazado para complementar la determinación de la pena o de otras consecuencias

51 MIR PUIG, Derecho Penal Parte General, 2002, 638. Por otro lado, ZAFFARONI le denomina "concurso ideal impropio" ya que la llamada concurrencia aparente o también impropia contempla los supuestos en que sólo en apariencia dos o más leyes penales concurren, pero que, en realidad, una de las leyes concurrentes excluye a las restantes. ZAFFARONI, Tratado de Derecho Penal Parte General, 1988, 547.

52 MIR PUIG, Derecho Penal Parte General, 2002, 638.

53 Lo característico de la combinación es que establece un marco penal dentro del cual deberá imponerse la pena definitiva; el límite máximo de ese marco se determina eligiendo el límite máximo más elevado de las penas individuales; mientras que el límite mínimo del marco se obtiene de aquel límite inferior que sea el más elevado de todas las penas individuales. 


\section{Revista de Derecho}

aplicables, reflejándose este modo la aplicación del principio de combinación. ${ }^{53}$

De tal modo que el límite mínimo de la pena señalada por el precepto desplazado es superior al del precepto desplazante, por lo que no podrá imponerse una pena inferior a la establecida en el precepto desplazado. Ello sucede cuando de la aplicación de un precepto como más grave va a resultar una pena más leve que lo que corresponde, lo que es posible en algún caso, debido a que las penas se señalan con un máximo y un mínimo. Para evitar que la norma del delito más grave acabe en una pena más leve, se propone en la doctrina que el límite máximo de la pena del delito leve opere como límite mínimo de la correspondiente al delito grave (idea de la «combinación de las leyes» en concurso).

Por su parte la Profesora Ingeborg PUPPE ${ }^{44}$ sostiene básicamente que el único lugar propio para la teoría del concurso (aparente) de leyes es el de la especialidad en sentido lógico formal, y es por ello que conceptualmente corresponde tratarlo al final de los planteamientos monistas ${ }^{55}$, ya que representa el más restringido de todos ellos. ${ }^{56}$

Nuestra norma penal no define qué es lo que debe entenderse por concurso aparente de leyes, más bien lo refiere a reglas de aplicación del concurso aparente tales como el de especialidad, el de subsidiariedad, el de consunción y en el principio de alternatividad. ${ }^{57}$

\subsection{Principios de solución del concurso o reglas}

Para dirimir el problema de la interpretación de distintas normas penales la doctrina ha elaborado diversos principios o reglas que sirven

54 Este carácter estrictamente monista de la variante de Puppe le otorga una ventaja indudable sobre los restantes sistemas que hemos expuesto, ventaja que radica en su precisión, su sencillez y, sobre todo, en su operatividad práctica, pues reduce el ámbito de la teoría del concurso (aparente) de leyes a los únicos casos en los cuales reina un cierto acuerdo, tanto en sus criterios de determinación como en los de solución. Esto último, sin tomar en cuenta que, además, este criterio es el único que responde a un principio universalmente aceptado, que proviene del propio Derecho Romano, y cuya salvaguardia parece haber sido el objetivo que se planteó Merkel al fundar la teoría cuyo desarrollo histórico en Alemania hemos expuesto en estos dos artículos. MATUS, La Teoría del Concurso (Aparente) de Leyes en la Dogmática Alemana, 2001, (en línea).

55 HÖPFNER, BELING, KLUG, HRUSCHKA, GÖSSEL, MONTENBRUCK, son algunos de los doctrinarios de la Escuela Monista que pueden consultarse para ampliar al respecto sobre la temática. De igual forma a JAKOBS y PUPPE quienes son autores de las nuevas posiciones monistas y el principio de especialidad dentro del concurso

56 MATUS, La Teoría del Concurso (Aparente) de Leyes en la Dogmática Alemana, 2001, (en línea).

57 Véase artículo 11 Ley $\mathrm{N}^{\circ} 641$, Código Penal de Nicaragua. 
de guía que, son generalmente aceptados dentro de la doctrina y que la legislación penal vigente regula en el artículo 11, los cuales estudiaremos a continuación.

\subsubsection{Principio de especialidad}

Según este principio existe concurso de leyes cuando de los varios preceptos aparentemente concurrentes uno de ellos contempla más específicamente el hecho que los otros, por lo que el concurso de leyes deberá resolverse aplicando la ley especial - lex specialis derogat legex generalis: la ley especial deroga la general-, por ello se afirma que la ley especial desplaza a la ley general..$^{8}$

Beling afirma que "en los casos de especialidad el typus specialis abarca completamenteal typus generalis", luego sólodeél ha dehacersedepender la punibilidad o no del autor; en cambio, en los casos de concurso de leyes, al presentarse los tipos en relación de neutralidad "la afirmación del primario no es siempre, conceptual y necesariamente, también la afirmación del otro, sino que depende de las circunstancias del caso concreto": la punibilidad o no del autor no depende sólo de la del tipo primario, sino también de que se haya realizado o no el subsidiario. ${ }^{59}$

Por su parte Puppe, asevera que hay concurso (aparente) de leyes sólo en los casos en que exista entre las disposiciones legales en juego una relación de especialidad en su sentido lógico o estricto, esto es, cuando una de las descripciones legales contiene todos los elementos de la otra más uno o varios especializados, o lo que es igual, en los casos de "especialidad" del sistema clásico y todos los otros en que tal relación se presente. En los restantes supuestos que la doctrina del sistema clásico señala como de concurso (aparente) de leyes, esto es, en la mayor parte de los de subsidiariedad y en casi todos los de consunción, afirma la autora citada, debe entenderse existe concurso ideal. ${ }^{60}$

58 El literal a) del artículo 11 del Código Penal vigente estipula como una de las reglas que la norma especial prevalece sobre la general. Puede ahondarse en el tema de manera doctrinal en QUINTERO OLIVARES, MORALES PRATS, Comentarios al Nuevo Código Penal, 1996, 66; RODRÍGUEZ MOURULLO, Comentarios al Código Penal, 1997, 47-48; MIR PUIG, Derecho Penal Parte General, 2002, 640 y MUÑOZ CONDE, Derecho Penal Parte General, 1998, 521.

59 MATUS, La Teoría del Concurso (Aparente) de Leyes en la Dogmática Alemana, 2001, (en línea).

60 MATUS, La Teoría del Concurso (Aparente) de Leyes en la Dogmática Alemana, 2001, (en línea). 
Normalmente el fenómeno se presenta entre los tipos básicos y agravados o atenuados, en los que se observa subordinación o inclusión entre uno $\mathrm{u}$ otro precepto. Por ejemplo, el dar muerte a una persona puede generar un concurso aparente de leyes respecto del homicidio y el asesinato, dos preceptos que engloban el dar muerte a una persona pero a diferencia del homicidio el asesinato reúne otras características que lo hacen especial, como son las circunstancias que agravan la realización de ese hecho - la alevosía, ensañamiento, precio, recompensa o promesa remuneratoria - en nuestra legislación. Estas circunstancias agravantes ${ }^{61}$ también pueden verse manifestadas en otros delitos, sin embargo constituyen agravantes genéricos y no especiales como los que especifica el artículo 140 del Código Penal en el que se aborda el asesinato, que puede verse reflejado en el principio de consunción mediante la absorción.

Según KÖHLER, en estos casos, "la razón por la cual no se aplican simultáneamente ambos supuestos de hecho, el más extenso y el más estricto, es el principio de que un mismo supuesto de hecho legal no debe aplicarse dos veces a un mismo suceso histórico, es decir, primero como parte del supuesto de hecho más estricto y luego como el supuesto de hecho más extenso e independiente. Esta es agrega Köhler sólo una consecuencia material del principio ne bis in idem". ${ }^{62}$

Otro ejemplo:

Tipo A

(Robo simple)

\begin{tabular}{|c|c|c|}
\hline $\begin{array}{l}\text { Apoderamiento } \\
\text { ilegítimo }\end{array}$ & $\begin{array}{l}\text { Cosa mueble, total o } \\
\text { parcialmente ajena. }\end{array}$ & $\begin{array}{l}\text { Con fuerza en las cosas o violencia } \\
\text { física sobre las personas }\end{array}$ \\
\hline
\end{tabular}

Tipo B

(Hurto simple)

Apoderamiento ilegítimo
Cosa mueble, total o parcialmente ajena.

61 El artículo 36 en sus incisos 1, 3,6 de la Ley Nº 641, Código Penal de Nicaragua, estipula como agravantes de la responsabilidad penal genéricos, entre otros, a la alevosía, el móvil de interés económico y al ensañamiento, de tal forma que cuando se aplica el asesinato no podrán invocarse dichas circunstancias ya que el precepto especial ya lo trae consigo; no así todas las otras que puedan llegar a concurrir y que no constituyen parte del precepto, por ejemplo el envenenamiento, prevalimiento en razón del género, discriminación, entre otras circunstancias.

62 MATUS, La Teoría del Concurso (Aparente) de Leyes en la Dogmática Alemana, 2001, (en línea). 
Como puede verse en este gráfico, y de acuerdo al principio de especialidad ${ }^{63}$, el tipo penal de hurto resulta desplazado (o implicado) por el de robo, dado que éste último contiene, además de los elementos típicos exigidos por el hurto, otro más que altera su estructura respecto del mismo.

\subsubsection{Principio de Subsidiariedad}

Aquí el precepto penal únicamente pretende regir en el caso de que no entre en juego otro precepto penal, es así que el primer precepto subsidia al segundo - lex primaria derogat legem subsidiariam: la ley primaria deroga la subsidiaria-, la cual se utiliza cuando la principal no es aplicable, es decir, la norma desplazada entra en juego sólo en defecto de la prioritaria.

La relación lógica entre dos enunciados o preceptos es la de interferencia, es decir, que el grupo de casos de una descripción normativa coincide, calza parcialmente con el de otra. De ahí que puedan darse tres clases de hechos a saber:

a. Hechos que se incluyen en el primer conjunto pero no en el segundo,

b. Hechos que se incluyen en el segundo, pero no en el primero; y

c. Hechos que se incluyen en el primero y en el segundo.

Por tanto, en la realización de un hecho consumado (lesiones consumadas), pueda que se realicen hechos que queden incompletos, (tentativa de lesiones); pero además hay que recordar que para pasar a la fase de consumación habrá que pasar antes por la fase de tentativa para dar comienzo a la lesión propiamente dicha. En lo que podemos concluir que, de esta relación lógica de interferencia permite que, en defecto del tipo de lesiones consumadas, se dé entrada al de tentativa de lesiones.

63 Según PUPPE, este emparentamiento entre delitos admite diversos grados, pero cuando se trata de casos de especialidad en sentido estricto o lógico, el emparentamiento sería tal que bastaría con aplicar sólo la norma especial para abarcar todo el contenido de injusto del hecho, sin necesidad de incorporar la norma desplazada en la medición de la pena de la desplazante -lo cual sería además del todo inapropiado respecto a los delitos privilegiados-, como sucedería en los casos de concurso ideal. Conforme a lo anterior, regularía solamente casos en que no exista tal emparentamiento o se trate de supuestos del llamado concurso ideal homogéneo, donde no existe la posibilidad de una doble valoración, ya que entre los supuestos de hecho concurrentes no habría ningún elemento de injusto común. MATUS, La Teoría del Concurso (Aparente) de Leyes en la Dogmática Alemana, 2001, (en línea). 
Por otro lado, MUÑOZ CONDE ${ }^{64}$ refiere que cuando alguien coopera en la realización de un delito y en su contribución no puede calificarse de cooperación necesaria se aplicará el precepto que regula la complicidad. Por ende, este principio es una forma de evitar que la no concurrencia de determinados requisitos deje sin sanción un hecho que, de todos modos, puede ser sancionado por otro precepto que no exige esos requisitos.

El literal b) del artículo 11 del Código Penal vigente, establece que dicho precepto subsidiario sólo se aplicará en defecto del principal, ya sea de forma expresa como tácita. ${ }^{65}$ Todo lo anterior nos refiere que, dicho principio aplica cuando en un precepto se dice que su aplicación queda condicionada a la no aplicación de otro, como sucede en el artículo 234 Código Penal ${ }^{66}$, en donde tácitamente la norma envía a que se aplique la misma pena del fraude en la entrega de cosas cuando se trate de viviendas u obras públicas. Lo mismo sucede en el caso de la estafa ${ }^{67}$ cuando quien con propósito de obtener un provecho ilícito, consiga transferencia no consentida de cualquier activo patrimonial en perjuicio de tercero.

ORTS BERENGER Y GONZÁLEZCUSSAC ${ }^{68}$ nos explican que en el fondo, la relación entre norma principal y norma subsidiaria no se diferencia mucho de la existencia entre norma general y norma especial. Por ello se observa que la regla de solución entre una y otra sea tan diversa, a tal punto que ellos afirman que la subsidiariedad es una variedad de la especialidad, aseveración con la cual concuerdo.

64 MUÑOZ CONDE, Derecho Penal Parte General, 1998, 522.

65 Deberá entenderse, según establece el código penal, como tácita cuando la subsidiariedad sea deducible.

66 Artículo 234 Ley N 641, Código Penal de Nicaragua. Fraude en la entrega de cosas. "Quien engañe en la sustancia, calidad o cantidad de las cosas que debe hacer o entregar, o de los materiales que debe emplear para realizar una obra que le ha sido encargada, será penado con prisión de uno a tres años y de noventa a ciento cincuenta días multa, cuando lo defraudado sea mayor de dos salarios mínimos del sector industrial. La pena de prisión será de tres a cinco años y de ciento cincuenta a trescientos días multa cuando se trate de productos de consumo o distribución masiva. Básico o de primera necesidad, objetos de valor artístico u otros sometidos a control oficial. Si el valor de las cosas por hacer o entregar, o los materiales a emplear sea superior a veinte salarios mínimos del sector industrial, la pena será de tres a siete años de prisión. La misma pena se aplicará cuando se trate de viviendas u obras públicas."

67 Artículo 229 Ley N 641, Código Penal de Nicaragua. Estafa. “Quien con el propósito de obtener un provecho ilícito, para sí o para un tercero, mediante ardid o engaño, induzca o mantenga en error a otra persona para que realiza una disposición total o parcial sobre el patrimonio propio o ajeno, siempre que el valor del perjuicio patrimonial exceda la suma equivalente a dos salarios mínimos mensuales del sector industrial, será penado con prisión de uno a cuatro años y de noventa a trescientos días multa. La misma pena se impondrá a quien con el propósito de obtener un provecho ilícito, consiga la transferencia no consentida de cualquier activo patrimonial en perjuicio de tercero, mediante manipulación de registros informáticos o programas de computación o el uso artificio semejante."

68 ORTS BERENGUER, Compendio de Derecho Penal, 2004, 109. 


\subsubsection{Principio de consunción}

El Código Penal lo define como el precepto complejo o el precepto cuya infracción implique normalmente la de otra sanción menos grave absorberá a los que castiguen las infracciones consumidas en aquél. ${ }^{69}$

Esta regla sirve para resolver problemas como los que se plantean en el iter criminis, por ejemplo al pasar de una fase ejecutiva a otra en un hecho, cuando A y B deciden cometer un secuestro, lo planean, lo ponen en ejecución y lo consuman, no responden por la conspiración ni por tentativa de secuestro sino por el secuestro consumado porque el castigo de este último abarca todo el desvalor de las conductas realizadas por A y B.

En los delitos simples y complejos, lo ejemplificaremos con el que entra a robar en morada ajena se le aplica la norma contenida en el artículo 225 literal c) CP y no las del robo con fuerza en las cosas (Art. $223 \mathrm{CP}$ ) y el allanamiento ilegal (Art. $201 \mathrm{CP}$ ), porque ésta abarca todo el desvalor del comportamiento llevado acabo.

También podríamos mencionar el caso de falta penal de contaminación de recursos hídricos ${ }^{70}$ y los delitos relativos a la contaminación de suelo, aire y agua $^{71}$; infracciones penales que entran en concurso aparente de leyes ya que cuando la basura se descompone produce un residuo líquido llamado lixiviado que se infiltra en el suelo, el mismo proceso de descomposición genera metano, realizando con ambas infracciones le mismo daño al medio ambiente y a los recursos naturales, por lo que deberá de observarse con claridad los hechos para determinar el precepto que deberá aplicarse, ya que aún coincidiendo el mismo supuesto de hecho carece de sentido aplicar la falta cuando lo que cabría es la aplicación del delito.

69 Véase artículo 11 inc. c) Ley $\mathrm{N}^{\circ}$ 641, Código Penal de Nicaragua.

70 Artículo 553 Ley $\mathrm{N}^{\circ}$ 641, Código Penal de Nicaragua. Contaminación de recursos hídricos y zonas protegidos. "Quien arroje basura o desechos de cualquier naturaleza a los cauces de aguas pluviales, quebradas, ríos, lagos, lagunas, esteros, cañadas, playas, mares o cualquier otro lugar no destinado por la autoridad para ese fin, será sancionado de diez a treinta días multa o trabajo en beneficio de la comunidad de diez a treinta jornadas de dos horas diarias, si el hecho no constituye delito. Si la conducta realiza en una zona protegida, se impone de cien a doscientos días multa y trabajo en beneficio de la comunidad de cien a doscientas jornadas de dos horas diarias."

71 Artículo 365 Ley N 641, Código Penal de Nicaragua. Contaminación del suelo y subsuelo. "Quien directa o indirectamente, sin la debida autorización de la autoridad competente, y en contravención de las normas técnicas respectivas, descargue, depósito o infiltración de aguas residuales, líquidos o materiales químicos o bioquímicos, desechos o contaminantes tóxicos en los suelos o subsuelos, con peligro o daño para la salud, los recursos naturales, 
Cuando se trata de delitos de peligro y de lesión ${ }^{72}$ se evidencia la aplicación del principio de consunción por la confluencia de ambos delitos, promoviendo la represión de este último y el relegamiento del primero por ejemplo, cuando se conduce un vehículo con temeridad y pone en peligro la vida de otro usuario de la vía pública, al que acaba de arrollar y causar la muerte, es responsable de un homicidio imprudente (Art. $141 \mathrm{CP}$ ) y no por exposición de personas (Art. $159 \mathrm{CP}$ ), ya que la conducta agota el desvalor realizado, lo cual implicaría un bis in idem al querer sancionar tanto la conducta de peligro como la de lesión al bien jurídico afectado.

$\mathrm{Y}$ en los actos copenados, como cuando alguien se apodera de cosa mueble ajena y posteriormente la destruye, caso en el cual será hurto y no concurso entre este y daño ocasionado en el bien ajeno; o bien el que falsifica una moneda y luego la expende no incurre en cientos de delitos, sino en un solo delito.

Por su parte ORTS BERENGER Y GONZÁLEZ CUSSAC afirman que "el principio de consunción lleva a las últimas consecuencias los requerimientos del ne bis in idem, que son base fundamental del concurso de normas, pues si éste se asienta sobre la idea de vetar la duplicidad de sanciones para un mismo hecho, el de consunción lleva a proscribirla, incluso habiendo más de un mismo hecho, cuando la integridad del comportamiento de un sujeto es susceptible de una única valoración englobadora de la total desaprobación que aquél merece.”73 Y lo enuncian como la norma que abarca todo desvalor atribuido por el

\footnotetext{
la biodiversidad, la calidad del agua o de los ecosistemas en general, será sancionado con pena de dos a cinco años de prisión y de cien a mil días multa. Las penas establecidas en este artículo se reducirán en un tercio en

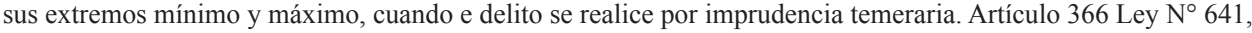
Código Penal de Nicaragua. Contaminación de aguas. "Quien directa o indirectamente, sin la debida autorización de la autoridad competente y en contravención de las normas técnicas respectivas, descargue, deposite o infiltre o permita el descargue, depósito o infiltración de aguas residuales, líquidos o materiales químicos o bioquímicos, desechos o contaminantes tóxicos en aguas marinas, ríos, cuencas y demás depósitos o corrientes de agua con peligro o daño para la salud, los recursos naturales, la biodiversidad, la calidad del agua o de los ecosistemas en general, será sancionado con pena de dos a cinco años de prisión y de cien a mil días multa. Se impondría la pena de cuatro a siete años de prisión, cuando con el objeto de ocultar la contaminación del agua, se utilicen volúmenes de agua mayores que los que generan las descargas de aguas residuales, contraviniendo así las normas técnicas que en materia ambiental establecen las condiciones particulares de los vertidos. Las penas establecidas en este artículo se reducirán en un tercio en sus extremos mínimo y máximo, cuando el delito se realice por imprudencia temeraria.

72 Los delitos de lesión exigen para su consumación que el bien jurídico protegido sea efectivamente lesionado. Los delitos de peligro no exigen para su consumación la lesión sino simplemente la puesta en peligro; basta la creación de una situación de posibilidad o contingencia que pudiera conducir a un resultado lesivo. 


\section{Revisla de Derecho}

ordenamiento jurídico a un hecho, desplaza a la que sólo aloja una parte de dicho desvalor. ${ }^{74}$

$\mathrm{Al}$ respecto ZAFFARONI, manifiesta que la diferencia entre el principio de consunción y el de especialidad está dado por el hecho de que en la especialidad hay un tipo penal que consume conceptualmente al otro, pudiendo y debiendo darse por realizado el consumido, mientras que en la consunción uno consume a otro pero no conceptuadamente sino materialmente, sin que sea necesario que en todos los eventos los dos se den por cumplidos. 75

\subsubsection{Principio de subsidiariedad impropia o de alternatividad}

Es conocido en la doctrina como una regla de recogida, cuando ninguno de los tres es aplicable; otros lo consideran como un principio más de los criterios de interpretación del concurso aparente, según el cual cuando dos tipos protectores del mismo bien jurídico contienen descripciones totalmente opuestas no pueden concursar porque se excluyen entre sí. ${ }^{7} \mathrm{El}$ legislador establece que cuando no sea posible la aplicación de alguna de las tres reglas anteriores, el precepto penal que sancione más gravemente excluirá a los que castiguen con menor pena. ${ }^{.7}$

MUÑOZ CONDE dice que debe siempre tenerse en cuenta este principio de alternatividad para evitar absurdas impunidades o despropósitos punitivos que pueden derivarse de una mala coordinación de los marcos penales de algunos tipos penales de estructura parecida, cuando no idéntica.

$\mathrm{Al}$ respecto en opinión de doctrinarios nicaragüenses este principio es utilizado como la primera opción y no como la última, dándole un trato de concurso medial y no como concurso aparente de leyes. Lo cual refleja una evidente confusión entre ambos preceptos.

Popularmente en Nicaragua, los privados de libertad la utilizan al expresar que en su caso "la pena grande se come a la pequeña", tratando de explicarse el que la aplicación de dicho principio se ve condicionada por la inaplicabilidad de la pena menor.

74 ORTS BERENGUER, Compendio de Derecho Penal, 2004, 110.

75 ZAFFARONI, Tratado de Derecho Penal Parte General, 1988, 562.

76 SANPEDRO ARRUBLA, Concurso de tipos penales, 2002, 307.

77 Véase artículo 11 inc. d) Ley N 641, Código Penal de Nicaragua. 
Entonces podríamos afirmar que en materia de concurso no es el que impone la aplicación del precepto más severo, sino el justo. De tal modo que en la aplicación de la norma que entra el judicial, prefiera imponer una pena más benévola ante una que pudiese verse como cruel.

\subsection{Incidencia del concurso aparente de leyes con el concurso ideal}

Si bien presenta notas comunes al concurso ideal es una institución del derecho, totalmente distinta. El punto en común es que es un solo hecho; la diferencia, radica en que cuando se trata de concurso ideal el hecho se adecua a dos o mas tipos penales que no se excluyen entre si; en tanto que cuando se trata de un concurso aparente, la adecuación múltiple es una ficción porque en realidad la adecuación es única, dado que los tipos penales en juego resultan incompatibles entre ellos y se desplazan en virtud de que resulta imposible su concurrencia simultánea. ${ }^{78}$

CUERDA RIEZU comparte pues la tesis expresada por PUPPE de que la prohibición de la doble valoración de unas mismas circunstancias de hecho exige el mantenimiento del concurso ideal con un régimen penológico más benigno que el del concurso real. ${ }^{79}$

\section{Punibilidad del concurso}

\subsection{Concurso efectivo ${ }^{80}$}

El articulado relativo al concurso aparente y al concurso de delitos manifiesta la pena a la cual estará sometido. Aunque el contenido de la norma es claro, no siempre la punibilidad del concurso se maneja de la misma manera. Para ello existen varios métodos o criterios para la regulación punitiva de los concursos que se utilizan en la doctrina, los cuales procederemos a mencionar.

7.1.1. Suma aritmética. Aquí las penas de los diferentes delitos cometidos se suman; así, si se presentan un concurso efectivo que se decida en sentencia deberá hacerse la suma aritmética de las dos sin

78 HASSEL, Derecho Penal Unidad 14 -, (en línea).

79 CUERDA RIEZU, El Concurso De Delitos, (en línea).

80 Respecto al concurso efectivo véase a SANPEDRO ARRUBLA, Concurso de tipos penales, 2002, 309 ss. 


\section{Recuista de Derecho}

que se supere el término máximo de la pena establecido como límite general.

Este criterio es muy criticado en vista que por esa vía podría llegarse a sancionar de manera desproporcionada, y desde los fines de la puede aparecer doble actuación de ella en el individuo, en tanto que con la aplicación de una de las sanciones se tiene por logrado mucho de lo que pretende la otra, lo que le haría perder el sentido.

7.1.2. Absorción. La pena a aplicar es la más grave de las previstas en los tipos concurrentes. En tanto la pena de mayor gravedad pasa hacer la principal. Se observa su aplicación en el concurso ideal y medial dentro de nuestro sistema jurídico penal.

Por ejemplo: Véase el caso de Falsificación material ${ }^{81}$ en donde la sanción va de uno a cuatro años de prisión y en la Estafa Agravada ${ }^{82}$ de tres a seis años y de trescientos a quinientos días multa, en el que el principio de absorción recae en el delito de Estafa Agravada.

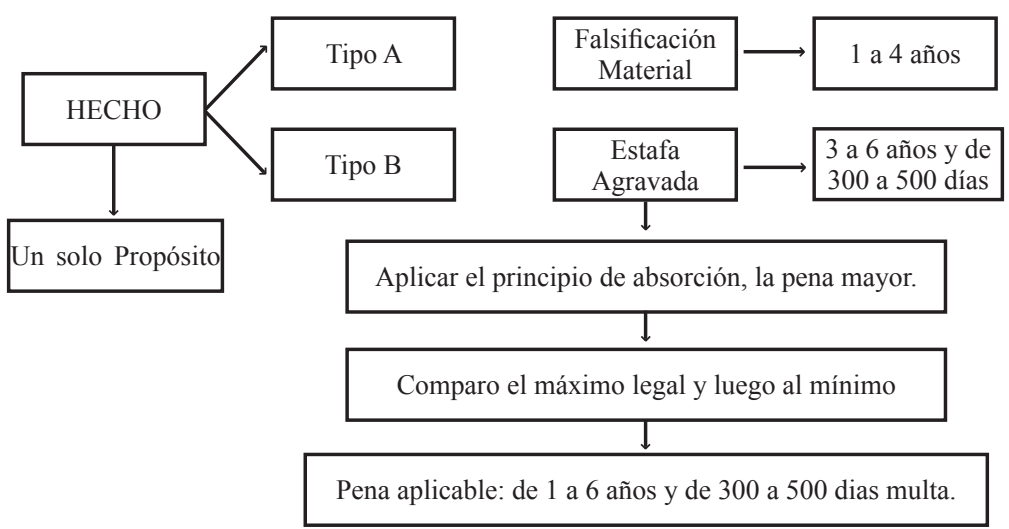

7.1.3. Aspersión. Se parte de la penas más grave de las establecidas para los tipos concurrentes, agravándola dependiendo de las previstas para los demás tipos que concursan, limitándose de ello siempre por máximos que hagan que en la práctica se llegue al uso del criterio de acumulación matemática.

81 Véase artículo 284 Ley $\mathrm{N}^{\circ}$ 641, Código Penal de Nicaragua.

82 Véase artículo 230 Ley $\mathrm{N}^{\circ}$ 641, Código Penal de Nicaragua. 
Por ejemplo, en el delito de violación ${ }^{83}$ se sanciona con pena de ocho a doce años de prisión. Por tanto, el mínimo sería de 8 años (mínimo mayor) y el máximo de 12 años (máximo legal a imponer según el artículo 167 CP si no concurre ninguna otra circunstancia. Acá debe observarse que la suma resultante de la acumulación de las penas correspondientes a imponerse por diversos hechos no podrá exceder del máximo legal de la especie de pena a imponerse, en este caso la de doce años.

7.1.4. Combinación. Algunos autores lo mencionan como uno de los criterios para la regulación punitiva de los concursos. El mismo actúa cuando en varias tipologías concurrentes se establecen pena de distinta naturaleza serán dosificadas conforme al criterio que de las anteriores se escojan las que tienen la misma naturaleza, y las demás se aplicarán normalmente.

Así, por ejemplo, si concurren dos delitos, de los cuales uno tiene pena de multa y los dos de prisión, se acumularán, sumarán, asperjarán o absorberán las de prisión y el resultante se combinará con la de multa. Se observa por ende, la presencia más clara del principio de combinación en casos del concurso real.

\subsection{Delito continuado y delito de masa}

A pesar de la pluralidad de acción, al haber unidad delictiva (unidad de culpabilidad), el delito continuado genera como principal consecuencia que los plurales hechos dependientes sean sancionados con una pena única, la del tipo penal que reiteradamente es llevado a cabo por el autor.

A diferencia de otras legislaciones penales, Nicaragua tiene regulado el delito continuado y el delito en masa es definido de manera independiente como una de sus modalidades, tal y como se describió con antelación. Es así que para el delito continuado se impondrá entonces la mitad superior de la pena señalada para la infracción más grave y en caso del delito en masa una pena agravada de hasta el doble del límite máximo.

Por tanto, sistema de absorción con agravación a favor de la pena más grave que corresponda imponer, véase acá el desarrollo del iter criminis, grado de participación, entre otros, e imposibilidad de ocasionar un saldo de pena. ${ }^{84}$

83 Véase artículo 167 Ley $N^{\circ}$ 641, Código Penal de Nicaragua

84 QUINTERO OLIVARES, VALLE MUÑIZ, Comentarios al Nuevo Código Penal, 1996, 414. 


\section{Análisis de casos concretos: Estudios de casos}

Ya anteriormente se dijo que el abordaje que se tiene respecto a la figura del concurso aparente de leyes y concurso de delitos en la actuación de los profesionales del derecho y los operadores de justicia es incorrecto. Para explicar tal aseveración y por efectos eminentemente académicos me permito presentar dos casos que fueron juzgados bajo el código penal de 1974 (Pn.), que se encontraba en vigencia al momento de cada uno de los procesos. No obstante, se realizará un estudio comparado entre lo expresado en dicho código sustento de las sentencias y la doctrina y el código penal vigente.

\subsection{Caso de estudio $N^{\mathrm{o}} 1$}

En el proceso incoado contra Mardon Pérez Madriz y Oscar Enrique Fornos Ruiz en perjuicio de Ervin Luis Hernández y Carlos Alberto Ramírez Howard (Q.E.P.D.) por el que actúa en calidad de ofendido su padre Carlos Alberto Ramírez Manzanares, acusados por los delitos de Robo con Intimidación en grado de Frustración con resultado de homicidio y Homicidio en grado de tentativa; expediente judicial iniciado bajo el proceso penal acusatorio y la normativa penal del Código Penal de 1974.

El análisis del caso se efectuó teniendo a la vista la sentencia condenatoria número 74, en la que se expresa que el caso fue conocido por Tribunal de Jurado, quienes emitieron veredicto de culpabilidad en contra de los acusados por los delitos de Robo con Intimidación en grado de Frustración con resultado de homicidio y Homicidio en grado de tentativa. Que el debate de la pena fue muy diverso cuando se leen las pretensiones de las partes, en vista que la argumentación jurídica que se utiliza de parte de sujetos procesales involucrados son diversos en todas sus dimensiones.

\subsubsection{Alegatos de las partes}

Así el Ministerio Público solicitó la pena mínima de diez años de prisión respecto al Homicidio y en lo que respecta al Robo con Intimidación la pena de cinco años de prisión. Alegando las circunstancias agravantes estipuladas en el artículo 30 Pn en sus numerales 2, 8, 11 y 13, refiriéndose a que el hecho se ejecutó con alevosía; que se emplearon medios para debilitar la defensa o abusar de superioridad por parte de la víctima y que el hecho se ejecutó en cuadrilla y de noche. 


\section{Revista de Derecho}

Por su parte, el abogado acusador particular alego la presencia de un concurso real de delito (en el acta que se tiene a la vista no se expresa ningún tipo de argumento que fundamente la existencia del concurso), hace alusión al artículo 89 del código penal de 1974 e invoca las agravantes expresadas en el articulo 30 Pn en sus numerales 1,11, 13 y 21, referidos a una mayor ilustración, educación y dignidad del delincuente; cometer el delito en cuadrilla; ejecutarlo de noche y ejecutar el hecho en la morada del ofendido.

Continúa argumentando el acusador particular que se logro demostrar dentro del proceso la presencia de cada una de las agravantes expresadas en vista que el acusado Mardon Pérez es estudiante universitario, que no actuó solo, sino en compañía de Oscar Fornos Ruiz; que los hechos fueron ejecutados entre las nueve y quince de la noche y en la casa de Carlos Alberto Ramírez (Q.E.P.D). Por lo que solicito la imposición de una pena de prisión de 25 años para cada uno de los acusados con motivo que el robo excedió los cinco mil córdobas.

Por otro lado, la defensa de Oscar Fornos Ruiz argumentó que se tome en cuenta que la acusación establecida por el Ministerio Público indica que la participación de su representado es de coautor en relación al delito de Robo con intimidación en grado de tentativa con resultado de muerte y por ser autor del delito de homicidio en grado de tentativa en perjuicio Ervin Luis Hernández. Que su representado no posee antecedentes penales y que no tuvo participación directa en la muerte de Carlos Alberto ni en la del vigilante. Por lo que solicita que la calificación del delito sea de acuerdo con la participación indirecta del mismo y se tome e cuenta la conducta anteriormente buena y la no existencia de antecedentes penales, además de que él es menor de veintiún años; por lo que solicita la pena mínima aplicable.

El representante de Mardon Pérez solicito que se tome en cuenta el numeral 2 del artículo 29 Pn, por ser éste menor de veintiún años de edad y que el mismo nunca ha sido detenido ni posee antecedentes penales. En lo que respecta a la autoría y participación manifiesta que lo deja a consideración de la autoridad competente para que éste emita las consideraciones que estime convenientes según la participación que tuvo su representado dentro de los hechos y que fueron demostrados en el proceso. Solicita por ende, la pena mínima para su representado. 
En ambos casos las defensas no abordaron ningún aspecto tocado por el Ministerio Público ni por el acusador particular. No hubo contra argumentación que debilitara las pretensiones de estos a efectos de imponer una pena justa para su representado y menos aún respecto al concurso real de delito expresado por el acusador particular.

\subsubsection{Fundamentos de Derecho expresados por el judicial}

A partir de folio trescientos sesenta y cinco de la sentencia es donde el judicial de primera instancia emite los fundamentos de derecho aplicables al caso y la tipicidad que al efecto pondrá según los hechos demostrados durante el proceso. Desde mi punto de vista, desde acá se observan inconsistencias en la motivación de la sentencia emitida; ya que el juzgador tipifica el hecho como Robo, dando la definición del mismo según lo establecido en el artículo 266 Pn, argumentando luego que "según la doctrina" establece que el delito de robo se agrava cuando con motivo u ocasión de cometerlo resultare homicidio.

En mi apreciación, no es cierto que la doctrina diga que el delito de robo se agrava cuando con motivo de cometerlo resulte la muerte de una persona (homicidio). Para ello es que la doctrina misma ha creado los concursos de delitos para que contribuya al judicial a la interpretación de la aplicación de la norma penal en todo su ámbito. En este caso en particular, el legislador de 1974 creo, como sucede en muchos casos, un tipo penal compuesto y le designó un tipo penal "robo con intimidación seguido de muerte” dándole una consecuencia jurídica más gravosa en razón de los elementos que hacen el delito un delito complejo.

Continúa expresando el judicial que a pesar de haber sido condenados por un veredicto de culpabilidad, se dejó claro que en la audiencia de debate de pena se consideró que durante el proceso no se probó el homicidio en grado de tentativa en perjuicio de Ervin Luis Hernández, por lo que no se atribuirá responsabilidad penal por el delito a los acusados. Siendo una actuación correcta procesalmente, al no demostrarse dentro de la práctica de la prueba los elementos necesarios que comprobaran la existencia de dicho delito.

Posteriormente en el ordinal número tres se evidencia la calificación de los hechos que realiza el judicial, tipificando entonces el caso como un Robo con intimidación con resultado de Homicidio, basándolo en la 


\section{Revisla de Perecho}

existencia de un concurso aparente de leyes, según lo dispuesto en los artículos 266 y 267 ordinal 1 Pn. Fundamenta la existencia del concurso aparente en el principio de especialidad y realiza su interpretación en la existencia de "idéntica validez temporal, idéntico ámbito especial de aplicación e identidad de conducta o hecho.”

Es evidente entonces, que en el caso existe valides temporal e idéntico ámbito espacial no así identidad de conducta o hecho. En tal sentido, no cabe bajo ninguna circunstancia hablar de concurso aparente de leyes, ni invocar el principio de especialidad, no hay norma general que tenga que ser desplazada por una especial, en tanto como he dicho anteriormente, el robo con intimidación seguido de muerte es un delito complejo creado y establecido así por el legislador en la norma penal, por tanto no está sujeto a concurso aparente de leyes por ser desde su nacimiento un delito autónomo como lo es el simple robo con intimidación, que el mismo legislador a impuesto una consecuencia jurídica exclusiva cuando sea cometido bajo las circunstancias especificadas en la norma.

Sírvasever quea laluz del código penal vigentelos hechos corresponderían a un encuadramiento en la figura del concurso medial, según el relato de los hechos que se hace en la sentencia. Además que en este momento la legislación ha dispuesto como delitos autónomos, al robo con intimidación y al homicidio, sin creación alguna de un tipo exclusivo que les englobe como en el pasado.

Se dice que es un concurso medial porque el fin último, según el relato de los hechos era la apropiación de un celular que estaba siendo impedida por las víctimas del delito motivo por el cual los acusados tuvieron que realizar otras acciones distintas pero bajo el mismo fin inicial de la preparación delictiva que era efectuar el robo con intimidación.

El judicial al respecto, continúa expresando que dentro del caso "se establece un tipo penal compuesto, existiendo un concurso aparente de normas, por dos actos a saber: El primero el del robo / el segundo, el del Homicidio".

Debe tenerse claro, que evidentemente existe un error en la motivación de la sentencia, ya que no hay tal concurso aparente de normas. Recordemos que la doctrina mayoritaria ha establecido que el concurso presupone que todos los preceptos en juego concurran de forma efectiva 


\section{Recuisla de Perecho}

según la infracción descrita, en este caso el robo con intimidación seguido de muerte (que es la tipificación que da el código penal de 1974) de modo que el hecho cabe en todos y cada uno de los preceptos posibles de aplicación, pero únicamente uno de ellos debe ser aplicado. Entonces, ¿cuál o cuáles serías los otros preceptos aplicables?

No es correcto pensar que los preceptos posibles de aplicación para el concurso a considerarse son el robo con intimidación y el homicidio. Véase que ambas acciones no son inclusivas una de la otra, pues para robar no es necesario matar y viceversa, para matar no es necesario robar intimidando.

Bajo este sentido se encuentra expresado la resolución que emite el judicial al condenar a los acusados por coautoría del delito de Robo con intimidación con resultado de Homicidio, imponiéndoles la pena de veintiuno años de prisión. Debe observarse que en ningún momento se expresa que para efectos interpretativos de la ley penal aplicable, encaja el concurso de normas a como lo viene estableciendo a lo largo de su fundamentación. Tampoco se refirió al concurso real invocado por el acusador particular.

Por ende, no hay en la sentencia analizada una respuesta coherente de fundamentación jurídica que permita tener los elementos necesarios y congruentes para demostrar un concurso aparente de leyes, ni a la luz del código penal de 1974, ni del código penal vigente.

\subsection{Caso estudio $N^{\circ} 2$}

En vista que a lo largo del presente trabajo he venido abordando los concursos de delito considero necesario ejemplificarlos también mediante estudios de caso, consolidando mi tesis respecto al poco conocimiento de los concursos en general.

En el proceso incoado contra José de Carmen Gómez Sánchez en perjuicio de Sergio Clever Maltez Rivas (Q.E.P.D.) acusado por el delito de Robo con intimidación seguido de muerte, expediente judicial iniciado bajo el proceso penal acusatorio y la normativa penal del Código Penal vigente.

Teniendo a la vista la sentencia condenatoria número 126 se procedió a efectuar el análisis del caso. El Tribunal de Jurado emitió veredicto de 
Revisla de Derecho

culpabilidad en contra del acusado por el delito de Robo con Intimidación seguido de muerte según el acta leída por el portavoz del Tribunal de Jurado.

\subsubsection{Alegatos de las partes}

El debate de la pena realizado por las partes, en primera instancia el Ministerio Público solicita la pena de 25 años de prisión en vista que la autoridad jurisdiccional calificara los hechos como un Robo con intimidación agravado en concurso ideal con asesinato de conformidad con los artículos 84, 224, 225 y $140 \mathrm{CP}$; invocando agravantes como la alevosía, premeditación, superioridad y actuación en cuadrilla según lo establecido en el artículo $30 \mathrm{CP}$.

Por su parte, la defensa solicitó la pena mínima de 21 años de prisión, rechazando la existencia de las agravantes de responsabilidad penal alegadas por el Ministerio Público.

\subsubsection{Fundamentos de Derecho expresados por el judicial}

Los fundamentos de Derecho se ventilan dentro de la sentencia a partir del folio 724; en la que el judicial realiza la vinculación de los tipos penales aplicables a los hechos demostrados en juicio.

Los tipos penales vinculantes expresados por el judicial en el caso son el robo y asesinato teniendo como base los artículos 224 y $225 \mathrm{CP}$, respecto al robo con intimidación y robo agravado incluyendo además el artículo 220 literal i) CP relativo a la cuantía de lo robado, y el artículo 140 CP del asesinato con el que expresa la existencia de concurso ideal de delito.

La fundamentación sobre el concurso ideal la establece el judicial por la existencia de unidad de hecho y pluralidad de infracciones, al probarse: la acción y el movimiento; acción y el resultado. Expresando que el factor final que rige el proceso causal es el mismo (robar y matar).

En tal sentido, considero que la fundamentación del concurso ideal en relación al robo con intimidación agravado en concurso con asesinato a como lo expresa el judicial no es objetivamente clara a la luz de los hechos probados según la relación de los hechos en sentencia. Si bien es cierto, el delito de robo con intimidación se consuma con el apoderamiento de 


\section{Revisla de Perecho}

la cosa y la potencial disponibilidad sobre la misma (el desprendimiento del canguro en el cual la víctima portaba el dinero).

Sin embargo, hay que recordar que la responsabilidad penal es de carácter individual. A tal efecto, en el caso planteado no se deja claro el grado de participación del acusado José del Carmen Gómez Sánchez en cada uno de los delitos. Se desprende de la misma lectura de la sentencia que la persona que disparó no fue él pero no se evidencia el conocimiento de éste sobre la utilización de la misma dentro del robo y así poder imputarle el grado de participación según los hechos cometidos. Todo esto es importante porque de ahí se desprende qué tipo de concurso debe aplicarse al caso.

Desde mi punto de vista, el concurso ideal es aplicable siempre y cuando se hubiese tipificado el caso como un robo con intimidación agravado en concurso ideal con homicidio no con asesinato, es un concurso ideal heterogéneo, así también lo refiere el judicial y está doctrinariamente correcto.

El plan preconcebido del que se habla es obviamente para robar pero no para matar. La muerte de la víctima se ocasiona producto del forcejeo y bien se menciona que es un cuarto participante que se encontraba en el vehículo quien dispara.

Para que se configure el asesinato debe de demostrarse alguna o todas las circunstancias de alevosía, ensañamiento, precio, recompensa o promesa remuneratoria, lo que no se evidencia en la sentencia en qué consistió cada una de ellas o cuál de las circunstancias es la aplicable para considerar el hecho un asesinato.

No obstante para la imposición de la pena la autoridad jurisdiccional valoró como acertadas las circunstancias agravantes de responsabilidad penal como lo es la alevosía, la cual no encaja para este caso, en vista que se ha tipificado los hechos como asesinato y desde su nacimiento dicho tipo penal trae consigo aparejada la circunstancia alevosa al igual que la circunstancia de ensañamiento.

Ambas circunstancias, a como mencionaba, son constitutivas del delito de asesinato y no deben ser doblemente penadas pues se cae en violentar el principio de ne bis in idem. 


\section{Revisla de Perecho}

En la imposición de la pena la autoridad jurisdiccional hace alusión al principio de absorción que aplicará en virtud de considerar que José del Carmen Gómez Sánchez actuó como autor del delito de robo con intimidación agravado en concurso ideal con asesinato yimponiendo una pena privativa de libertad de veinticinco años de prisión.

A como me he expresado con anterioridad, queda claro que en el caso estudiado no se efectuó un correcto análisis del tipo penal aplicable, pues dentro de la fundamentación rara vez se refirieron a daño patrimonial sufrido por la víctima quedando dicha circunstancia agravante sin relevancia alguna. Además del desacuerdo mencionado respecto si los hechos deben ser considerados como un asesinato o como un simple homicidio, que es mi posición.

\section{Conclusiones}

El concurso aparente deleyes o normas penales se encuentraíntimamente vinculado con el estudio de la interpretación de las leyes penales debido a la valoración que debe de realizarse para apreciar la viabilidad de si un hecho está contemplado o no en las norma y la decisión sobre en cuál encaja de manera más acabada y completa.

Sin embargo, hablar del concurso aparente de leyes no es posible sin abordar los concursos de delitos. A efecto, la legislación nicaragüense reconoce el concurso real, ideal, medial y al delito continuado. Ya en aseveraciones propias, mencionaba que el abordaje del delito en masa dentro del código es tácito.

Para efectos conceptuales cada concurso fue abordado tratando de esbozar un abanico de figuras para su estudio y poder brindar una amplitud de conocimiento al momento de abordar del concurso aparente de leyes. Ahí conocimos las debilidades que se tiene dentro del abordaje y planteamiento que se hace de cada uno de los concursos de delitos; que dentro del delito continuado no se toma en consideración para su motivación los elementos espacial y temporal de realización de los hechos para ser aplicable. Todo lo cual constituye una deficiencia en la forma de aplicar los concursos de delitos.

La doctrina ha sido variante y muy dinámica dentro del concurso aparente de normas o de leyes respecto al tratamiento de los principios de solución al concurso de leyes. Las nuevas tendencias de la escuela 


\section{Revisla de Derecho}

Monista, mediante Jakobs y Puppe, son los más críticos respecto a dicha teoría sin obviar los aportes significativos realizados por Klug, que impactó y repercutió en los planteamientos teóricos no solo de Jakobs y Puppe sino también a Hruschka y Gössel.

Se observa pues con este estudio que existe escasa doctrina sobre la temática y que existen muchas divergencias al respecto, más si se plantea el tema del concurso de normas. No obstante, en los recientes códigos penales aprobados en Iberoamérica se ha incluido al concurso aparente de leyes dentro de su normativa, constituyendo un gran avance en la aplicación de dicha figura dentro del Derecho Penal.

Por ello, la incorporación de la institución del concurso aparente de leyes dentro de la reforma de justicia penal Nicaragüense ha sido una buena decisión de parte de los legisladores; ya que a través de ellas, los operadores de justicia tendrán elementos fundamentados en la norma penal vigente que les permita en conjunto con la doctrina fundamentar con mayores elementos las sentencias penales que emiten.

La legislación penal a través del código penal vigente en su artículo 11 regula al concurso aparente de leyes que se sancionarán mediante la aplicación de cuatro principios, reglas o criterios de solución a saber: especialidad, subsidiariedad, precepto complejo (consunción) y cuando no sea posible la aplicación de alguna de las tres reglas anteriores (alternatividad).

Estos principios o criterios se podrían resumir en básicos y complementarios. Básicos, el de especialidad y el de consunción en tanto que los de subsidiariedad expresa o tácita y el de alternatividad tan sólo pueden operar cuando la meta necesaria, que siempre será dar sentido penal pleno, y en su caso, específico, a lo sucedido, no haya podido alcanzarse. Por lo tanto, el orden de enumeración es un orden sucesivo pero en la práctica la subsidiariedad operará para lo no resuelto por la especialidad y la alternatividad lo hará cuando no baste la consunción.

El análisis de los casos presentados me permitió demostrar la afirmación respecto a la incorrecta interpretación y aplicación de la norma y doctrina misma referente al concurso aparente de leyes y de delitos. Se afirma entonces, que la técnica jurídica aplicada de parte de los operadores judiciales y abogados litigantes no es la más idónea y que su conocimiento respecto a las figuras es muy escueto. 


\section{Recomendaciones}

Luego de haber estudiado la figura del concurso aparente de leyes y de conocer las dificultades que la figura presenta ante su aplicación, considero realizar las recomendaciones siguientes:

- Revisar los programas de la asignatura de Derecho Penal de las Facultades de Ciencias Jurídicas para incluir actividades de aprendizaje concretas que permitan profundizar en el estudio del concurso de delitos y el concurso aparente de leyes en las aulas de clases para que la nueva generación de licenciados en Derecho tenga mayores y mejores herramientas que les permitan visualizar la buena o mala aplicación de las mismas en las sentencias penales.

- Difundir a través de capacitaciones, talleres, seminarios, foros o congresos dirigidos a abogados, funcionarios públicos y estudiantes de Derecho, el estudio del concurso de delitos y el concurso aparente de leyes ya que la intervención de todos estos actores permitirá el enriquecimiento pleno por las diversas experiencias en que intervienen dentro del sistema de justicia penal.

\section{BIBLIOGRAFÍA}

\section{Obras:}

1.- ARCE AGGEO Miguel Ángel, Concurso de delitos en materia penal, Editorial Universidad, Buenos Aires, 1996.

2.- BANADES GASSET Ramón, Conceptos Fundamentales del Derecho, Las relaciones jurídicas patrimoniales. 6ta edición, Marcombo, Barcelona, 1982.

3.- FERNÁNDEZ MARTÍNEZ Juan Manuel (Coordinador) Diccionario Jurídico, Arazandi, Navarra, 2002.

4.- MIR PUIG, Santiago, Derecho Penal Parte General, 6ta. Edición, Editorial Reppertor, Barcelona, 2002.

5.- MUÑOZ CONDE Francisco y GARCÍA ARAN Mercedes. Derecho Penal Parte General, 3ra. edición. Tirant lo Blanch, Valencia, 1998.

6.- ORTS BERENGUER Enrique y GONZÁLEZ CUSSAC José. (Coordinadores) Compendio de Derecho Penal Parte General y Parte Especial, Tirant lo Blanch, Valencia, 2004.

7.- QUINTERO OLIVARES, Gonzalo (Director), Comentarios al Nuevo Código Penal, Arazandi, Pamplona, 1996.

8.- RODRÍGUEZ MOURULLO, Gonzálo (Director), Comentarios al Código Penal, Civitas, Madrid, 1997. 
9.- SANPEDRO ARRUBLA Camilo, Lección 18: Concurso de tipos penales, $1^{\circ}$ Edición, Universidad Externado de Colombia, 2002.

10.- TIJERINO PACHECO José María; GÓMEZ COLOMER Juan Luis, (Coordinadores) 2da Edición, Manual de Derecho Procesal Penal Nicaragüense., Tirant Lo Blanch, Valencia, 2006.

11.- VIVES ANTON Tomás (Coordinador), Comentarios al Código Penal 1995 Volumen 1(Art.1 a 233), Tirant lo Blanch, Valencia, 1996. 12.- ZAFFARONI Eugenio Raúl. Tratado de Derecho Penal Parte

General. Tomo III y IV. Ediar., Buenos Aires, 1988.

13.- ZAFFARONI, Raúl Eugenio, Manual de Derecho Penal. Parte

General, 6ª edición, Ediar, Buenos Aires, 1994.

\section{Legislación:}

14.- Constitución Política de Nicaragua, publicada en La Gaceta Diario Oficial $\mathrm{N}^{\circ} 5$ del 05 de enero de 1987.

15.- Ley No 641, Código Penal de la República de Nicaragua, publicada en La Gaceta Diario Oficial No 83, 84, 85, 86 y 87 en 05, 06, 07, o8 y o9 de mayo de 2008.

16.- Ley No 406, Código Procesal Penal de la República de Nicaragua, publicada en La Gaceta Diario Oficial N ${ }^{\circ} 243$ y 244 del 21 y 24 de diciembre del 2001.

\section{Páginas de Internet:}

17.- CUERDA RIEZU, Antonio, El Concurso de Delitos en el Borrador de Anteproyecto de Código Penal de 199o, (en línea). Consultado el 28 de abril 2009.

18.- HASSEL, Guillermo, Derecho Penal Unidad 14-Unidady Pluralidad Delictiva, (en línea), Consultado 29 de abril 2009. Disponible en Internet: www.monografias.com

19.- MATUS, Jean Pierre, La Teoría del Concurso (Aparente) de Leyes en la Dogmática Alemana, desde sus Orígenes hasta el Presente (Segunda Parte), ISSN 0718-0012 versión en-línea, Ius et Praxis Año 7 No 2: 357 - 400, 2001. Consultado el 29 de abril 2009. Disponible en Internet: http://www.scielo.cl/scielo.php?pid=So71800122001000200016\&script=sci_arttext 


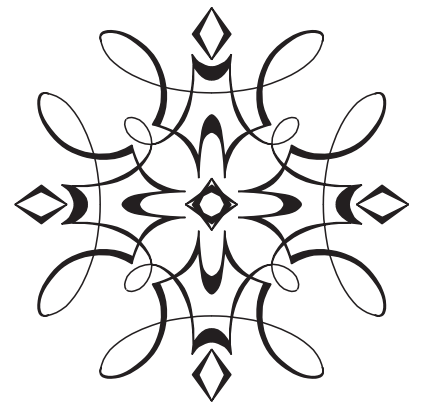

